\title{
Assessing the Adoption of a Home Health Provisioning System in India: an analysis of doctors' knowledge, attitudes and perceptions
}

\author{
N Agarwal, MP Sebastian and S Agarwal
}

\begin{abstract}
Background: Unlike developed countries, home healthcare provision systems (HHPS) are not widely prevalent in developing countries like India. Our objective was to study the knowledge, attitudes and perceptions of doctors in India about the adoption of HHPS.
\end{abstract}

Methods: Our survey included 180 doctors across India, working in local hospitals. Using online and paperbased questionnaires, we used bar charts and pie charts to represent the frequency distributions. We also conducted multivariate logistic regression analysis to understand the importance of the selected factors upon the dependent variables of interest such as willingness to work during non-office hours, desire for increased remuneration, and willingness to enrol in HHPS.

Results: The desire for an increase in remuneration made doctors more willing to enrol in HHPS. Possible reasons for doctors to enrol included the ability to answer follow-up queries through email or video chat and HHPS being integrated with the local healthcare system in the hospital. Young male doctors were most likely willing to provide services through HHPS during nonoffice hours as compared to females. A large majority of doctors indicated hospital visits to be important for follow-up queries, but several doctors indicated that simple patient queries could be addressed by nonpersonal interactions like video chat or email.

Conclusions: The desire for extra remuneration could be the primary reason for the willingness of doctors to work during non-office hours and thus enrol in HHPS. The majority of doctors considered hospital visits to be important, but several doctors also indicated that nonpersonal interactions using text messages, telephone, email and video chat might serve as important methods to respond to simple follow-up queries from patients.

Abbreviations: EMR - Electronic Medical Record; HHPS - Home Help Provisioning Systems; ICT - Information and Communication Technology; ISO - International Organisation for Standardisation.

Key words: concierge medicine; technology adoption; EMR; home healthcare; services; ICT.

\section{Nikunj Agarwal}

Department of Information Technology and Systems Indian Institute of Management

Kozhikode, Kerala, India.

\section{MP Sebastian}

Department of Information Technology and Systems Indian Institute of Management

Kozhikode, Kerala, India.

\section{Shikhar Agarwal}

Department of Interventional Cardiology

Cleveland Clinic

Cleveland $\mathrm{OH}, \mathrm{USA}$

Correspondence:

nikunj05fpm@iimk.ac.in

\section{Introduction}

Home Health Provisioning Systems (HHPS) represent an arrangement where physicians provide routine, emergent, as well as 'enhanced' healthcare services, in patients' homes. $[1,2]$ As a part of the system, patients are generally provided emergency as well as routine primary healthcare services. [2] These systems have several benefits, which include enhancing the convenience for patients and allowing supplemental fees for doctors. They primarily provide more personalised care to patients as the appointments are for a longer time as compared to traditional hospital visits. Moreover, a solid physician-patient relationship is established, and there is 24-hour access to doctors. [3,4] 
These systems become financially more viable because there is provision for routine as well as expanded primary healthcare services in addition to emergency healthcare services. [2] Although these systems are in existence in many developed countries, they are yet to be introduced in developing countries like India. This form of healthcare service practice is known by various names, most commonly 'concierge medicine,' 'boutique medicine,' 'access fee practice,' or 'retainer practice'. [1] In this paper, we refer to this healthcare service practice as HHPS. The aim of the study is to understand whether the doctors in a developing country like India would welcome the idea of HHPS to improve the healthcare of patients. This study aims to evaluate the feasibility and the factors that will be important for the implementation of such a system from the doctors' viewpoint.

According to the International Organization for Standardization (ISO), the electronic medical record (EMR) is the repository of patient data in digital form, stored and exchanged securely and is accessible by multiple authorised users. [5] Previous studies have demonstrated that the EMR improves the quality of care, hence improving the efficiency of overall healthcare outcomes. [6,7] Improving patient related outcomes, reducing medical errors and improving the overall efficiency in healthcare settings have been achieved by the implementation of the EMR. $[7,8]$ The majority of healthcare institutions in developing countries still use paper-based records for writing prescriptions for patients. These systems have been in existence for a long time. Unlike developed countries, EMR use is not widespread in all healthcare settings of developing countries like India. There is limited research literature available on doctors' perceptions about EMRs playing a role in the adoption of a HHPS in India. We hypothesise that using EMR would be instrumental in the successful implementation of HHPS in India due to the increased accessibility from remote areas.

Multiple questions have been raised regarding the widespread implementation of HHPS. Concerns include an increase in existing healthcare inequities along with the abandonment of patients by their physicians, based on income and ability to pay. [2] These systems have illdefined payment systems, as they may be considered 'out of network' by most conventional insurance plans. [2] They may also pose a risk of insurance fraud due to the possibility of duplicate billing by the practising physicians, as most of the physicians have traditional practices as well. [2] Moreover, several of these practices can result in healthcare overuse. $[2,7,8]$
Despite these controversies regarding the benefits and risks associated with a HHPS, there appears to be scant evidence regarding the perceptions of doctors towards its use. The majority of articles represent anecdotal evidence or consensus statements. [2] A large proportion of HHPS physicians provided specialised services such as accompanied specialist visits, house calls, 24-hour physician access, same day appointments, coordinated hospital care, as well as private waiting rooms, which are often lacking in traditional physician practice. $[2,12]$

These are some of the reasons why HHPS is being contemplated by patients: after-hours access, same day scheduling and non-personal interactions. However, to the best of our knowledge, there is no systematic evaluation of doctor attitudes, beliefs and perceptions regarding HHPS and related systems available in the current literature. There is scant knowledge about the factors (i) affecting the enrolment of doctors into HHPS and (ii) influencing doctors to provide services through HHPS during non-office hours. The HHPS could be initially planned as a local or a statebased system. Due to the unique payment structure that exists in India, where most patients are uninsured, the system could be planned as a 'fee for service system'. It is also possible to implement HHPS in a discrete geographic location as a 'subscription based' system. Under this system, all the members would be required to pay a fixed annual fee, depending on the clinical comorbidity burden, and could avail the HHPS services, on a need basis. Complex feasibility analysis based on the financial viability of these systems continues to be a potential research topic.

In a survey conducted in 2007 , only $28 \%$ of patients had access to medical care during non-office hours. The patients would be able to access medical care only when the doctors were willing to provide services through in person office visits, or house calls or video conferences. Moreover, to the best of our knowledge, there is scant research on the importance of factors such as demographics (age and gender) of doctors likely to have interest in HHPS, and the benefits of information and communication technologies (ICT) in its implementation. With this background, we attempted to understand the needs, modes of accessibility, attitudes, and perceptions of doctors towards a system where different healthcare services can be utilised by doctors through a HHPS.

A few research perspectives have been identified earlier for consideration such as 'How much should a physician charge for a HHPS patient, and what service should the doctor 
provide?'. [9] However, there is scant research literature available on these aspects. The research literature available on the importance of factors such as the demographics of doctors that may influence their enrolment for service provision through HHPS (in terms of age, gender, and number of patients they see every day), compatibility of the HHPS with the needs of doctors, and the benefits of ICT for the adoption of HHPS is also limited. In this paper, we have made an attempt to understand the importance of the above factors in adopting HHPS.

The research aims to understand the factors influencing the adoption of HHPS by doctors in India. The research questions that we have attempted to address in this paper include the following. (1) What factors influence the enrolment of doctors in HHPS? (2) What is the likelihood of doctors utilising HHPS during non-office hours? (3) What is the desire for extra remuneration for doctors to provide services through HHPS?

\section{Methods}

\subsection{Study population}

The study population consisted of doctors from government and private hospitals in India. The study was conducted at Government Medical College Hospital Kozhikode, Baby Memorial Hospital Kozhikode, Malabar Institute of Medical Sciences Kozhikode, Cradle (Apollo) Kozhikode, All India Institute of Medical Sciences New Delhi, and Metro Hospital Kozhikode. The human resource departments in the respective hospitals were instrumental in helping us circulate the surveys through online and paper-based media. In addition, we circulated the questionnaires online using Survey Monkey and popular social media websites like Facebook, Twitter and LinkedIn.

\subsection{Study tool}

The tool used for the study was a questionnaire. We did a thorough literature review to understand the various factors that might be significant for the adoption of HHPS. We consulted healthcare providers in the United States (where HHPS is in use) and in India to understand the factors that may be important in HHPS adoption and whether these factors are relevant in the Indian healthcare context. We designed a comprehensive iterative questionnaire to include all these factors in a simple and coherent fashion. The questionnaire was first circulated among ten doctors for feedback to ensure that all the questions were interpreted as intended. The questionnaire was then modified based on the responses from the initial sample of doctors involved.
The questionnaires were initially disseminated through social media (Facebook, Twitter, and Linkedln). We then disseminated the survey directly to doctors by visiting the local hospitals of Kozhikode city. We provided souvenirs in the form of books to doctors who took part in the study, as a token of appreciation for their time.

\subsection{Study variables}

The outcome variables considered for the adoption of a HHPS were the willingness of doctors to work during nonoffice hours, willingness of doctors to enrol into HHPS and the desire for increased remuneration for the doctors to work in HHPS. The independent variables that we have considered for the study are shown in Appendix $A$ that appears at the end of this article.

\subsection{Statistical Analysis}

Statistical analysis was performed using Stata 12.1 (Stata Corporation, College Station, TX, United States). The Likert scales were collapsed to a dichotomous variable, 'important' (most important, important, and somewhat important) and 'not important' (least important, and less important) for this analysis. Differences in characteristics between the groups were tested for significance using the chi-square test. We performed a multivariable logistic regression analysis for the primary outcomes, after adjusting for all independent variables. Three separate regression models were constructed for the three outcome variables. Appendix A lists the different outcome and the independent variables considered for our study. We performed several subgroup analyses for each of the independent variables listed in the three tables based on age and gender.

\section{Results}

We collected a total of 32 responses from the online media, from which 18 (56.3\%) of the responses were excluded because the participants were not from India. Hence there were 14 usable responses collected through online media. We collected 180 responses through paper-based questionnaires, out of which 14 (7.8\%) responses were unusable, as doctors did not complete the questionnaires. A total of 180 (84.9\%) responses that were collected through online and paper-based media were included in the study.

Figure 1 demonstrates age-based stratification of perceptions of doctors about the EMR and its role in adoption of HHPS.

Figure 1B demonstrates that doctors of age groups 35 to 44 $(97.3 \%)(p=0.09)$ and greater than 44 years $(95.7 \%)(p=0.001)$ were currently working in hospitals with EMR facilities. 
Figure 1: Age-based stratification of perceptions of doctors on EMR and its role in adoption of HHPS
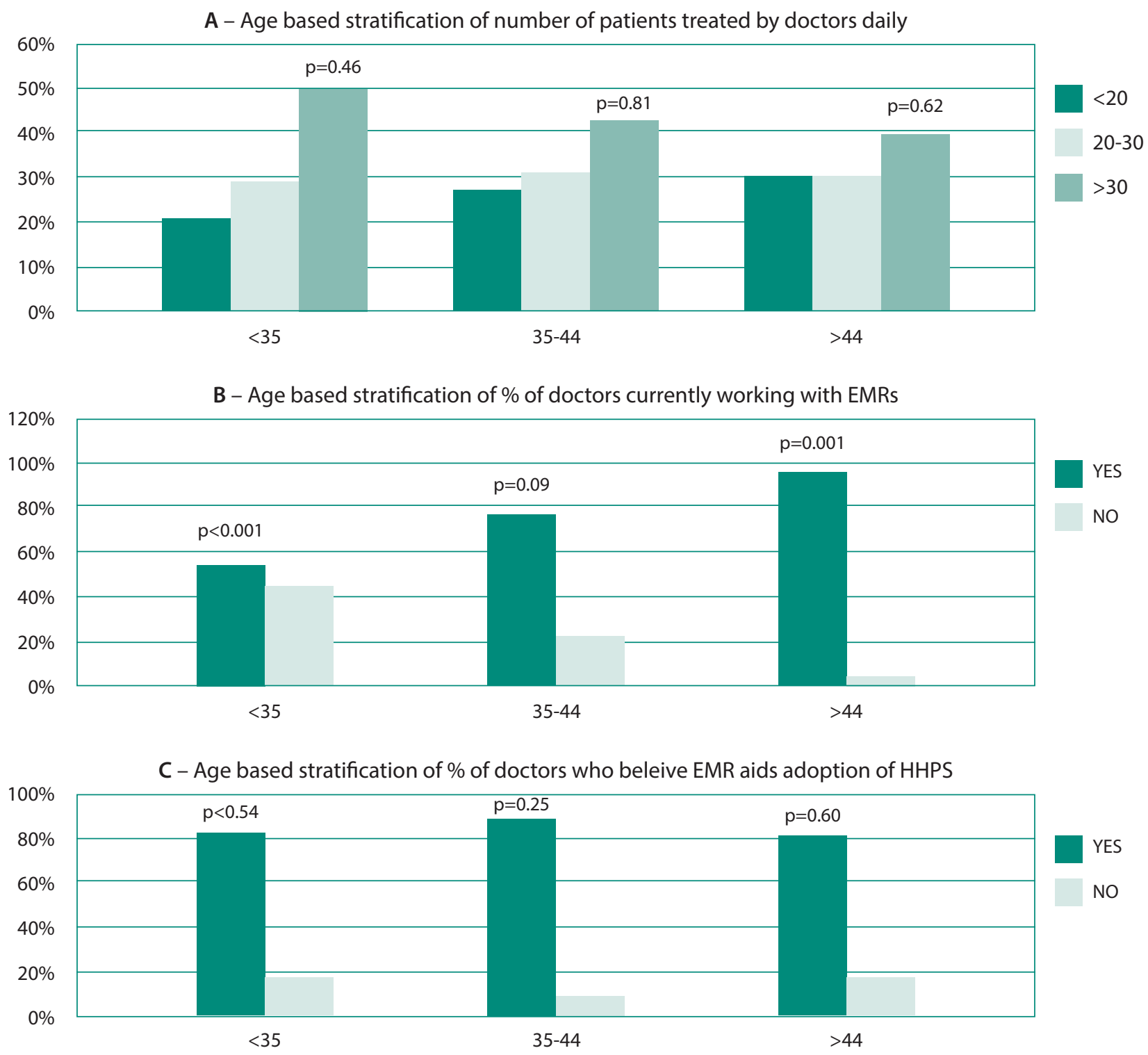

Figure $1 \mathrm{C}$ demonstrates that a large proportion of doctors in all age-based strata $(\mathrm{p}=0.54,0.25$, and 0.60 for age groups $<35,35-44$, and $>44$, respectively) believed that EMR would aid HHPS adoption in India. 
Figure 2 demonstrates gender-based stratification of perceptions of doctors about the EMR and its role in adoption of HHPS.

Figure $2 \mathrm{~A}$ demonstrates that out of all doctors, $44.5 \%$ of the male doctors and $55.8 \%$ of the female doctors treated more than 30 patients every day in the current hospital $(p=0.43)$.
Figure 2B shows that a large proportion of female doctors (69.3\%) were currently working in hospitals with EMR facilities. Figure $2 \mathrm{C}$ demonstrates that a large proportion of doctors in all gender-based $(p=0.31)$ believed that EMR would aid HHPS adoption in India.

\section{Figure 2: Gender-based stratification of perceptions of doctors on EMR and its role in adoption of HHPS}
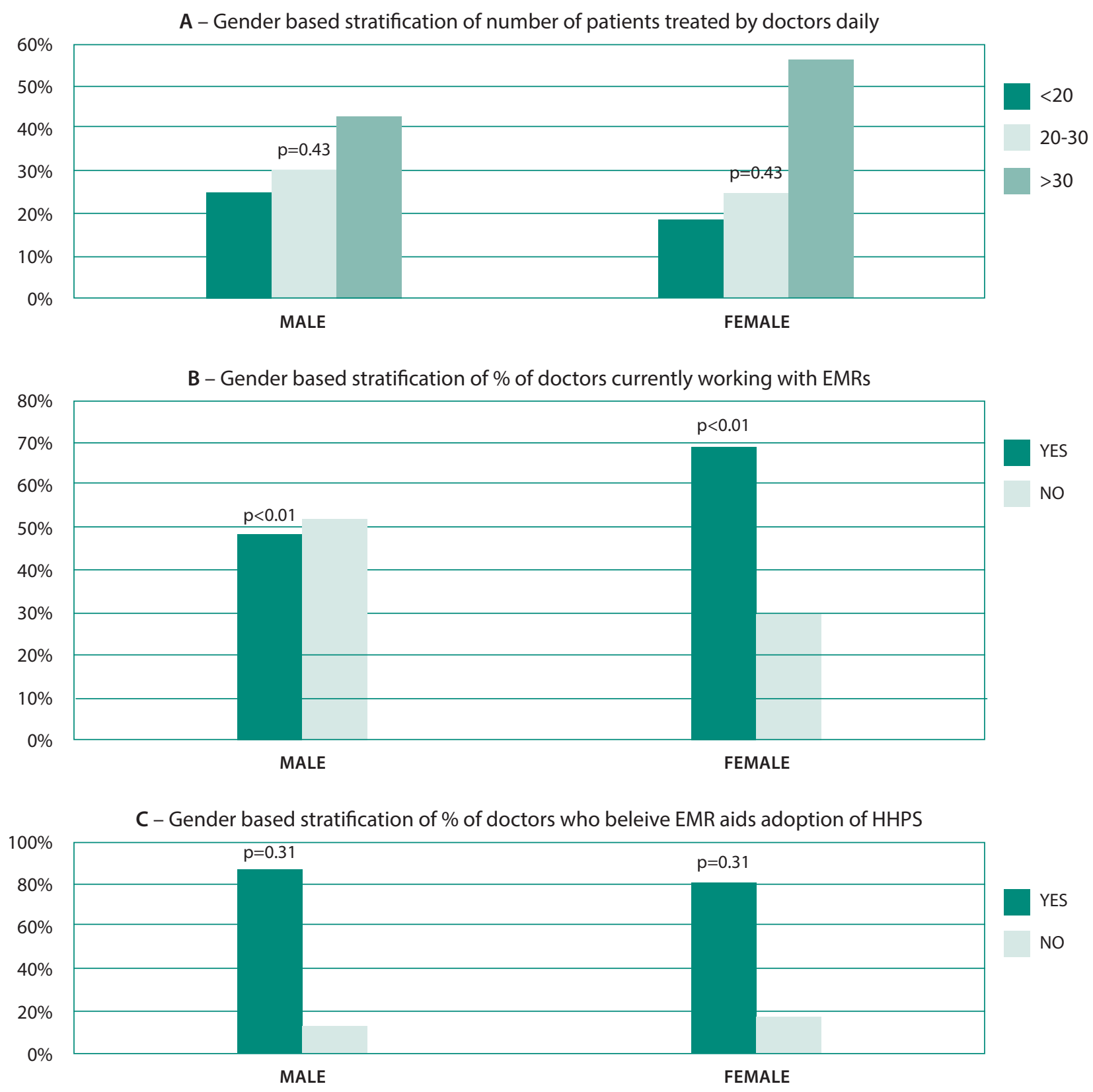
Figure 3 demonstrates the age-based stratification for willingness of doctors to provide services through HHPS.

Figure $3 \mathrm{~A}$ demonstrates that $95.0 \%$ of doctors of $<35$ years $(p=0.002), 78.4 \%$ of doctors of $35-44$ years $(p=0.008)$, and $82.6 \%$ of doctors of $>44$ years $(p=0.206)$ were willing to enrol in HHPS.
Figure $3 \mathrm{C}$ demonstrates that a large proportion of doctors $<35$ years of age $(88.3 \%)(p<0.001)$ were willing to work during non-office hours compared to those of age groups $35-44(56.8 \%)(p<0.001)$ and greater than 44 years $(65.2 \%)$ $(p=0.09)$.

\section{Figure 3: Age-based stratification for willingness of doctors towards provisioning of service through a $\mathrm{HH}$}

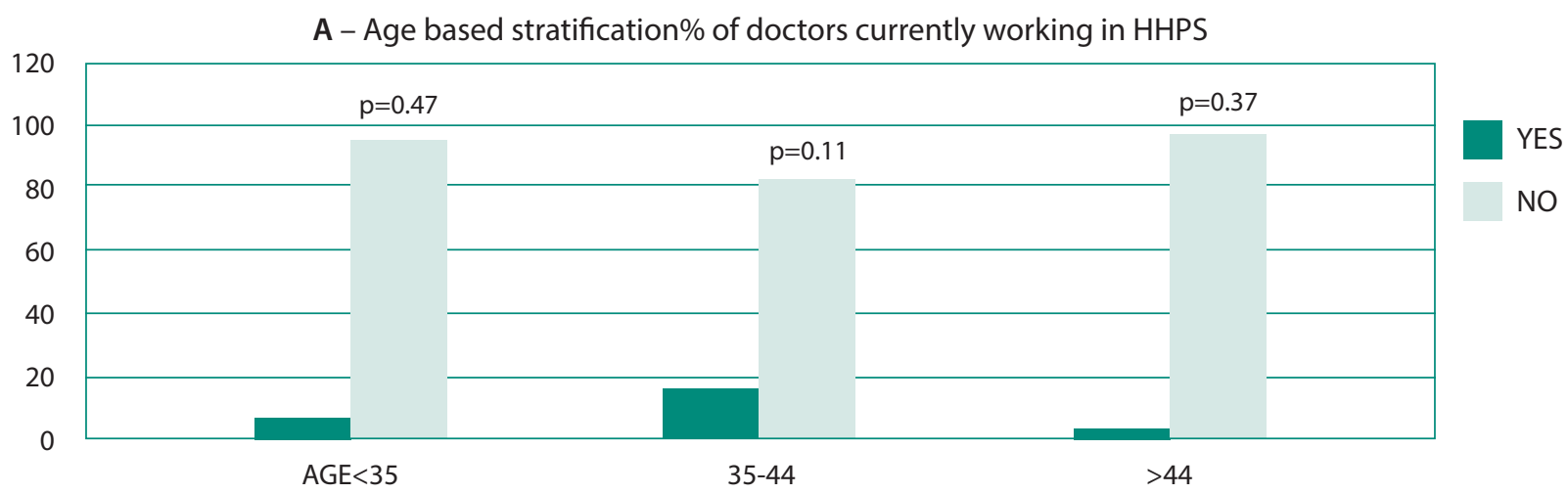

B - Age based stratification of \% of doctors willing to enroll into HHPS

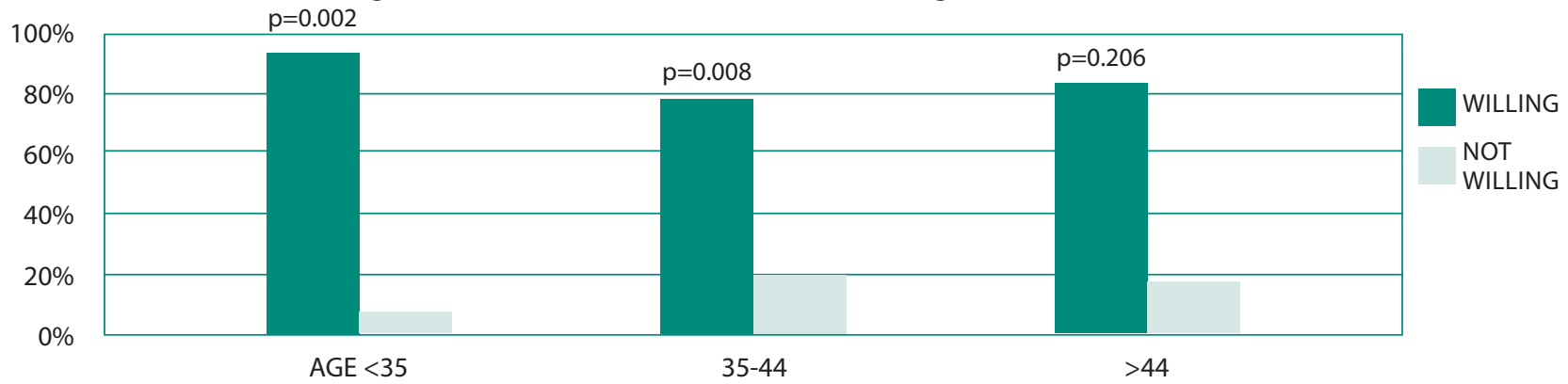

C - Age based stratification of \% of doctors willing to provide healthcare services during

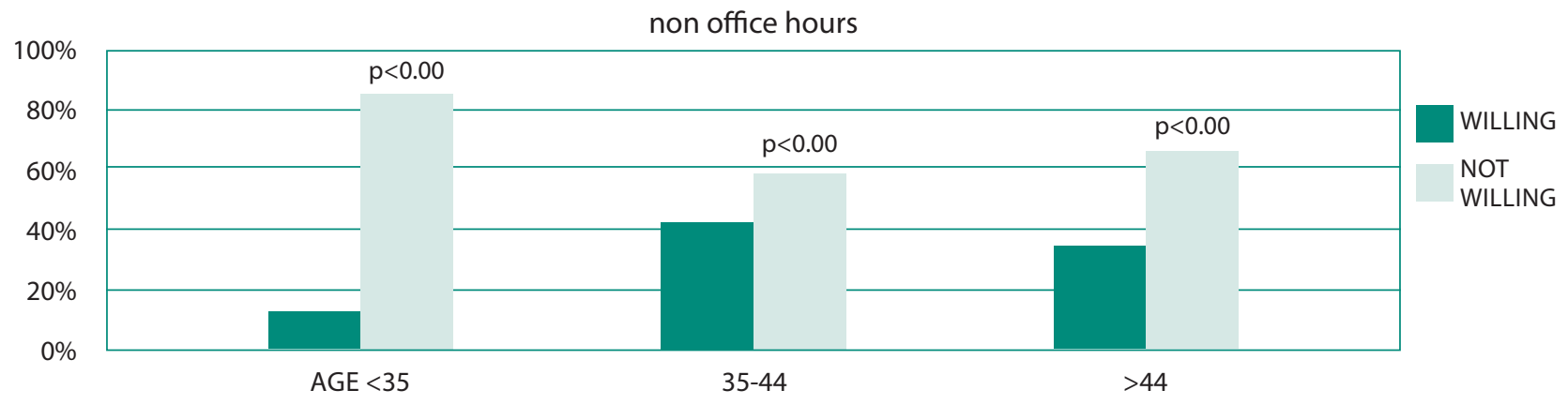


Figure 4 demonstrates gender-based stratification for willingness of doctors to provide services through HHPS.

Figure 4A demonstrates that a very small proportion of male (8.0\%) and female (13.0\%) doctors were currently providing services through HHPS $(p=0.25)$.
Figure 4B demonstrates that a significant proportion of male (90.5\%) and female (88.4\%) doctors were willing to enrol in HHPS $(p=0.68)$. A large proportion of male $(81.0 \%)$ and female $(72.1 \%)$ doctors were interested in working during nonoffice hours on weekdays and on weekends $(p=0.21)$.

Figure 4: Gender-based stratification for willingness of doctors towards provisioning of service through a HHPS
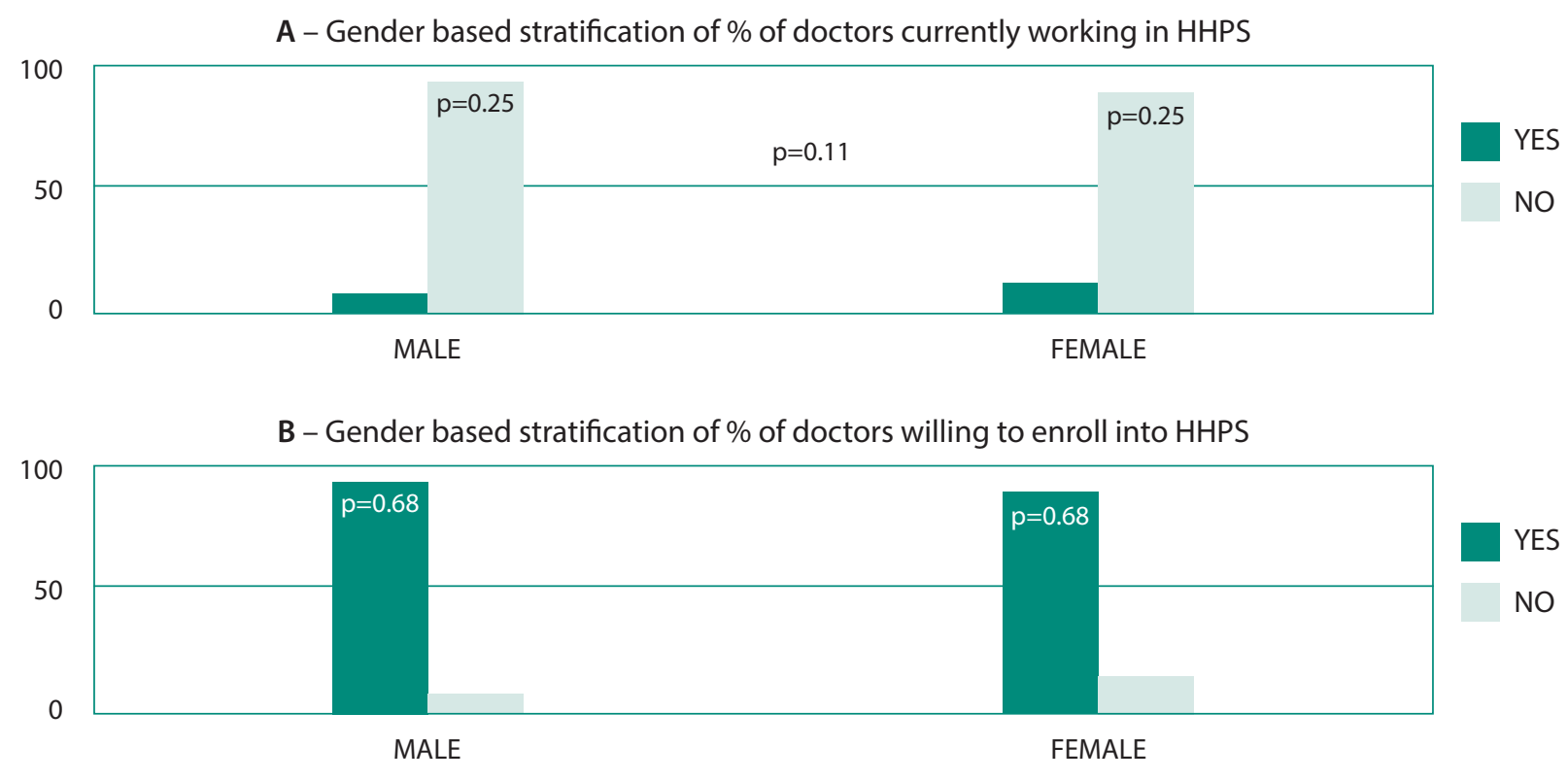

C - Gender based stratification of $\%$ of doctors willing to provide healthcare services during non office hours

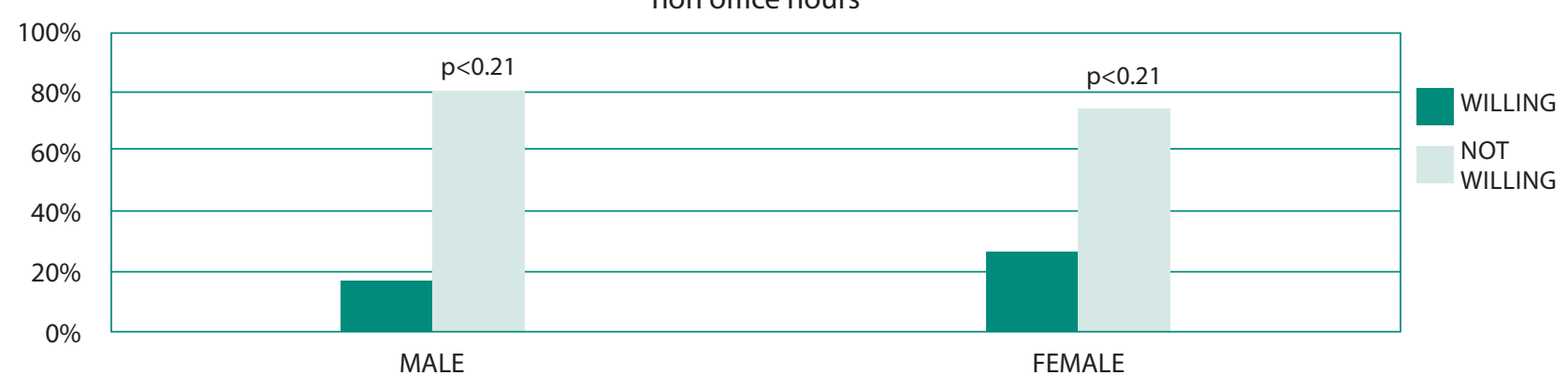


Figure 5 shows the perceptions of doctors about ICT and the other important factors in the adoption of HHPS.

Figure $5 \mathrm{~A}$ demonstrates that $45.0 \%$ of doctors were aware of routine check up provision through HHPS.

Figure 5B demonstrates several factors doctors deemed important for successful adoption of HHPS in India. Of the total responses, $95.6 \%$ believed that HHPS would need to be compatible with the needs of the patient community for its successful adoption Similarly, 93.9\% believed that HHPS would be successful if it could be easily integrated with the local hospital networks. In addition, $89.4 \%$ believed that a free trial for HHPS would be necessary before actually adopting this system. Furthermore, $89.4 \%$ of the doctors believed that accessibility of HHPS to interface remotely using hand-held devices would be a key factor for the successful adoption of this system. A large majority of doctors (79.4\%) believed that an extra monetary credit for doctors would also be an important factor.

Figure 5C demonstrates that majority of doctors (88.3\%) believed that hospital visits were important for follow-up on simple patient queries; several doctors believed that non-personal interactions might serve the purpose too in several cases. The proportion of doctors who believed that text messages, video chat, email or telephone calls may serve as important means of communication to respond to simple patient queries were $36.1 \%, 45.0 \%, 55.0 \%$ and $80.6 \%$, respectively.

\section{Figure 5: Perceptions of doctors about ICT and other factors important for the adoption of a HHPS}

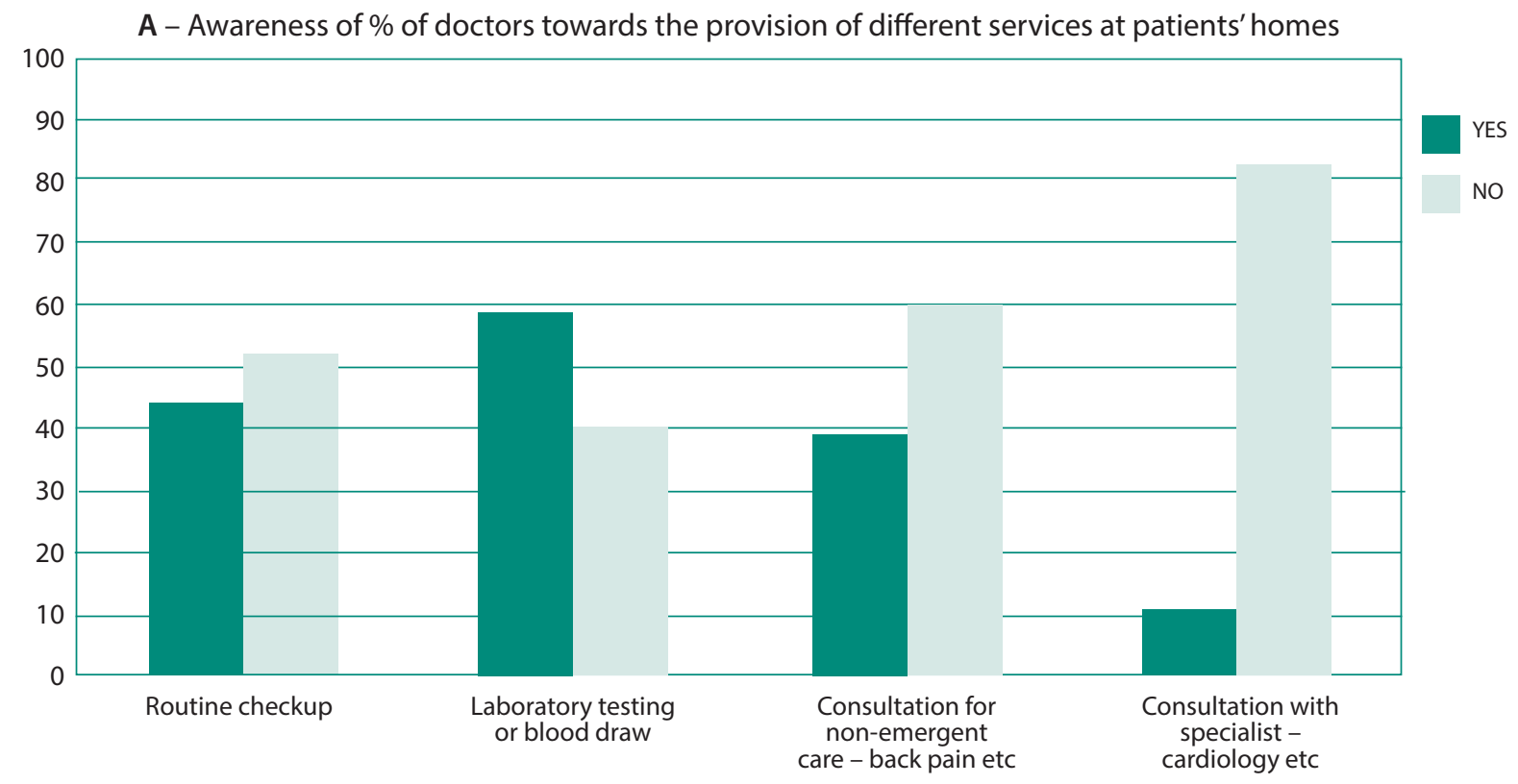

B - Perceptions of $\%$ of doctors towards importance of the following factors in the adoption of home healthcare services

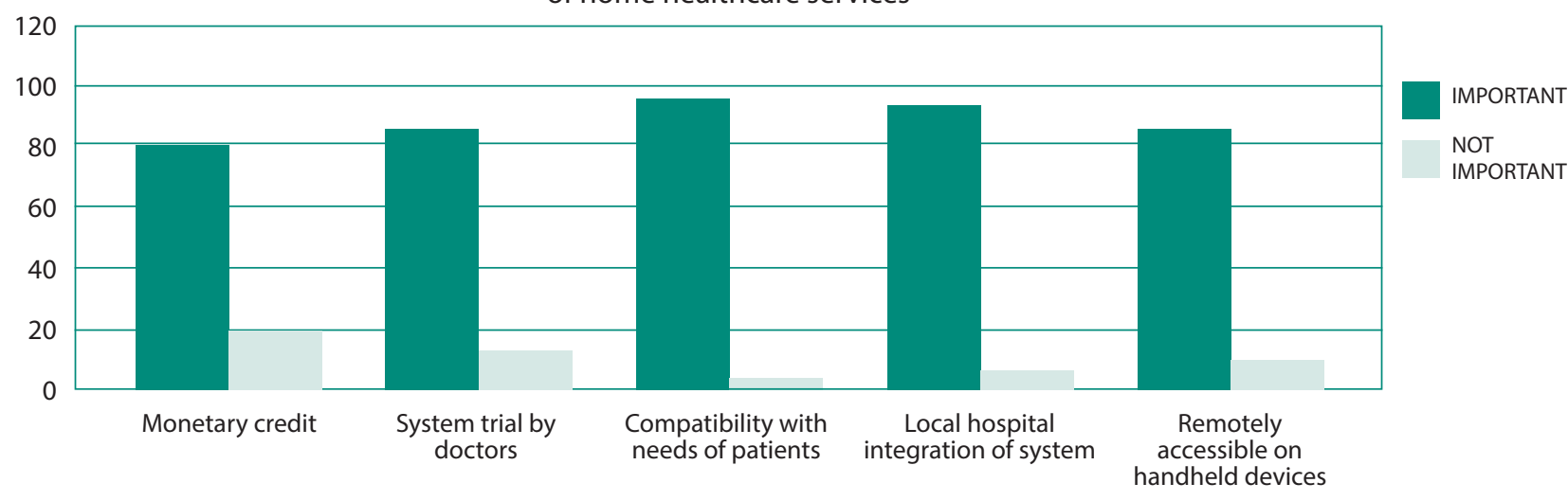


Figure 5: Perceptions of doctors about ICT and other factors important for the adoption of a HHPS continued

C - Perceptions of \% of doctors preference for the usage of information and communication technologies (ICT) to respond to simple patient queries

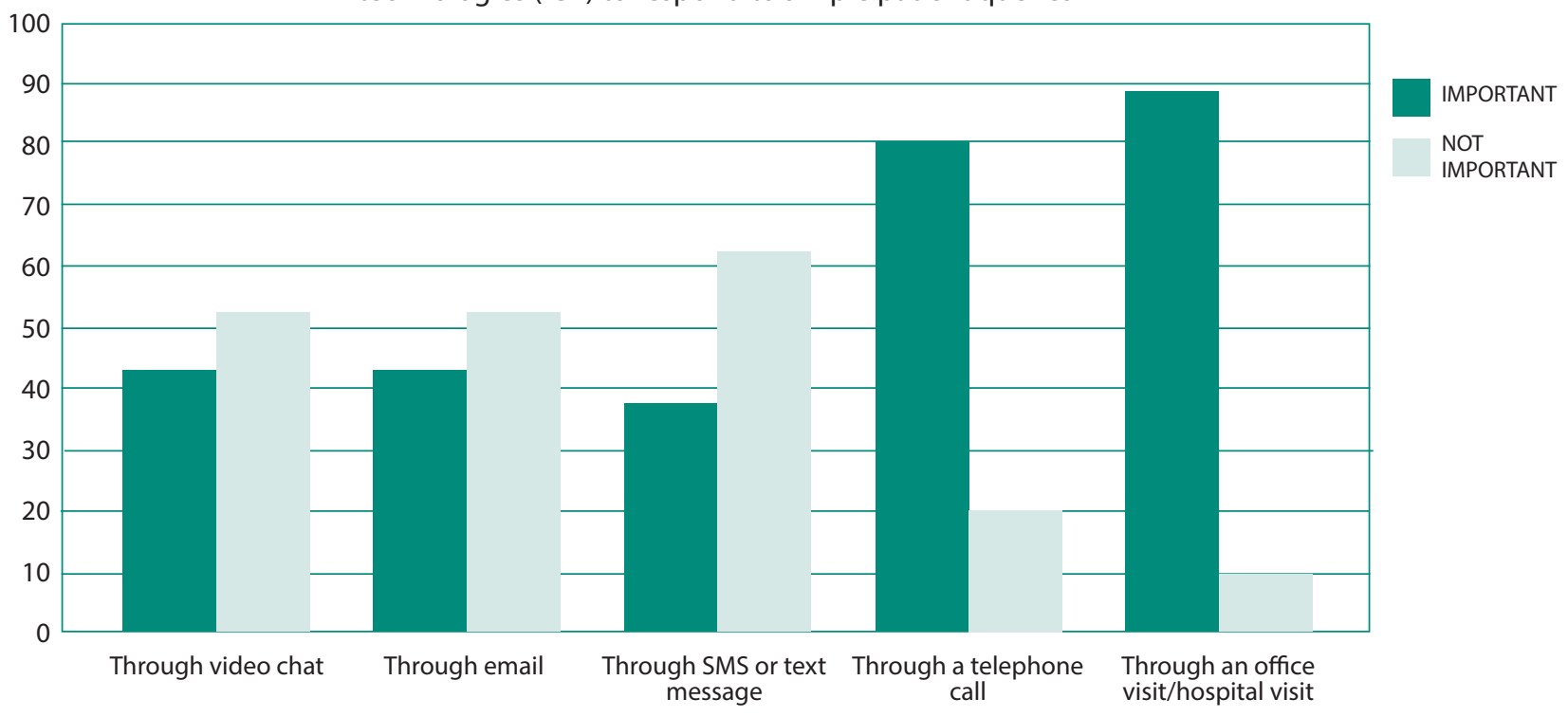

Figure 6 demonstrates the perceptions of doctors about costs, remuneration and important preferences of doctors for enrolment in HHPS. It can be seen from Figure $6 \mathrm{~A}$ that a significant proportion of doctors (95.6\%) desired an increase in remuneration. The proportion of doctors desiring a $20 \%$, $40 \%$ or $50 \%$ increase for service provision through HHPS were $27.8 \%, 32.2 \%$, and $28.30 \%$, respectively.
Figure $6 \mathrm{~B}$ shows the proportion of doctors expecting patients to pay $20 \%, 50 \%$, and $100 \%$ extra for the service provision through HHPS were $21.7 \%, 20.0 \%$, and $20.6 \%$, respectively.

Figure $6 \mathrm{C}$ shows that a large percentage (54.40\%) of doctors would enrol into HHPS upon a free trial.

\section{Figure 6: Perceptions of doctors about costs, remuneration, and preference of enrolment into a HHPS}

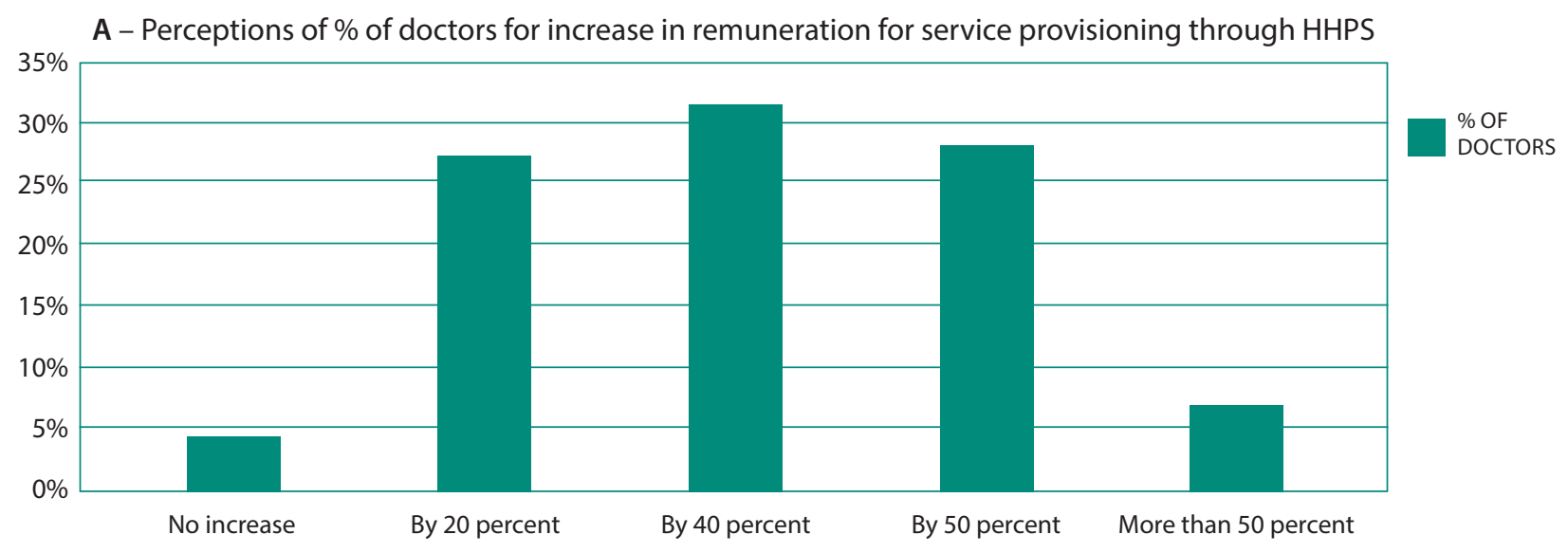


Assessing the Adoption of a Home Health Provisioning System in India: an analysis of doctors' knowledge, attitudes and perceptions

Figure 6: Perceptions of doctors about costs, remuneration, and preference of enrolment into a HHPS continued B - Perceptions of $\%$ of doctors towards extra charges that patients should pay for availing services through HHPS

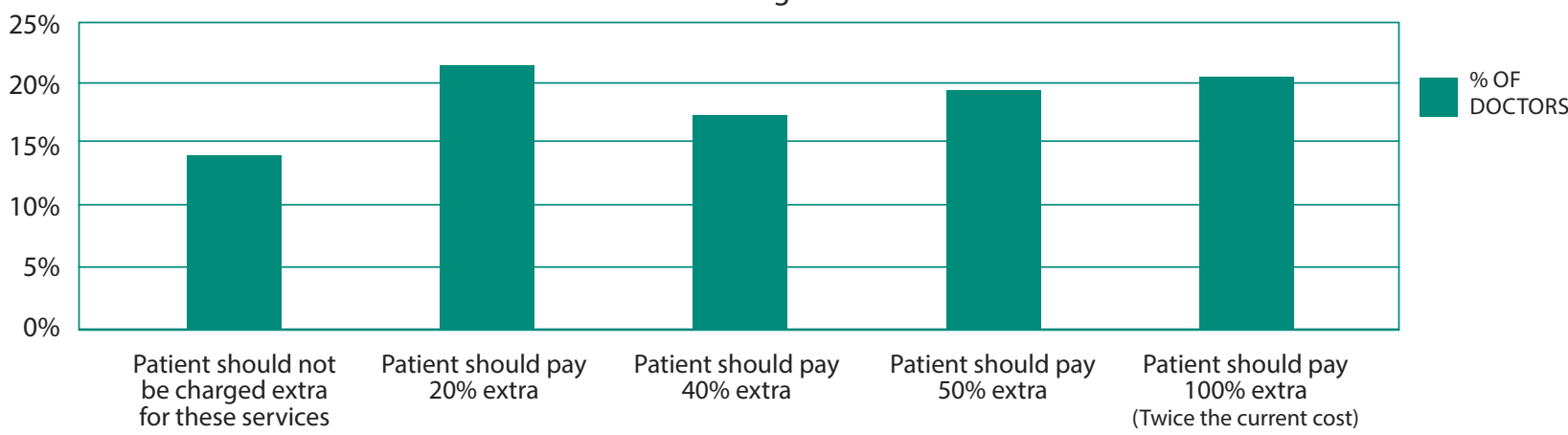

C - Preference of enrollment of $\%$ of doctors for HHPS

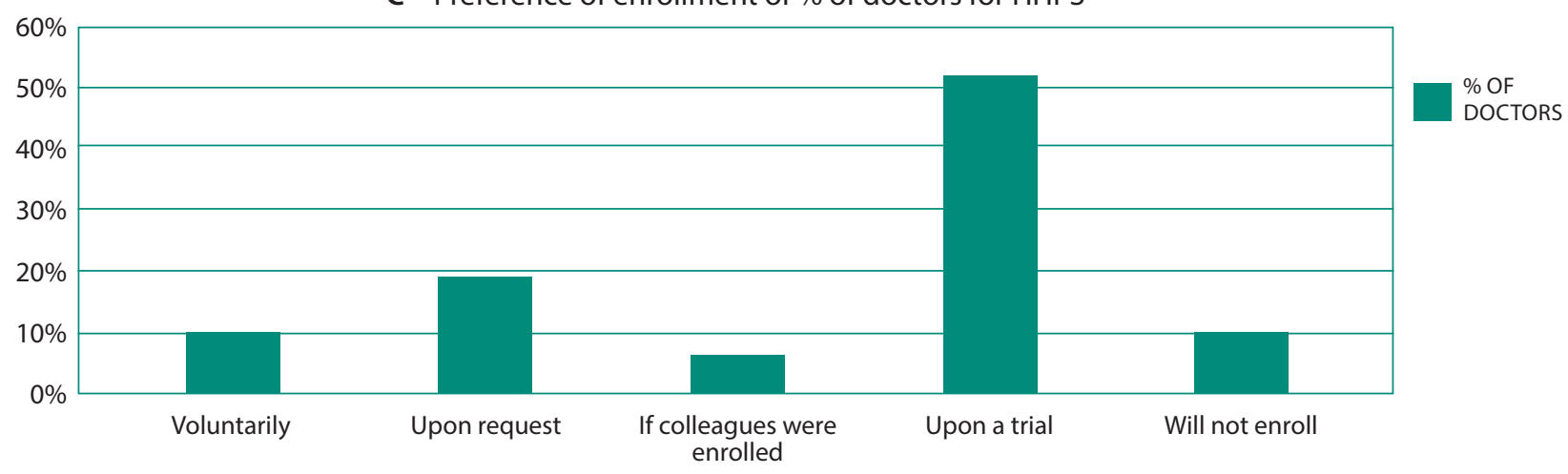

Appendix A: List of outcome and independent variables

\begin{tabular}{|c|c|}
\hline OUTCOME VARIABLES & INDEPENDENT VARIABLES \\
\hline $\begin{array}{l}\text { Willingness to work during } \\
\text { non-office hours }\end{array}$ & Number of patients seen every day in the hospital \\
\hline $\begin{array}{l}\text { Desire for an increase in } \\
\text { remuneration }\end{array}$ & Answering the follow-up queries by video chat or email \\
\hline \multirow[t]{13}{*}{ Willingness to enrol into HHPS } & Answering the follow up queries through text message or telephone call \\
\hline & The system leads into a trial by doctors before adoption \\
\hline & The system is compatible with the needs of patients in the community \\
\hline & The system is integrated with local healthcare system in hospital \\
\hline & $\begin{array}{l}\text { The system is accessible remotely on handheld devices to review patient } \\
\text { history at patient's home }\end{array}$ \\
\hline & Patients being charged extra for availing services through HHPS \\
\hline & I currently work in a system that has EMR \\
\hline & EMR simplifies the overall workflow \\
\hline & EMR aids the adoption of HHPS \\
\hline & Answer the follow up queries through a hospital visit \\
\hline & Age \\
\hline & Surgical specialties \\
\hline & Male \\
\hline
\end{tabular}

Note: A few outcome variables were used as independent variables in the multivariate regression models 
Appendix B lists the unadjusted comparisons stratified based on age. A significantly higher proportion of doctors $>44$ years of age $(95.7 \%)$ were employed in hospitals currently using EMR $(p<0.001)$. There was a significant variation in the desire for an increase in remuneration by age strata. Doctors aged $35-44$ years, $51.4 \%$ of them and $43.5 \%$ of doctors aged $>44$ years expressed desire for $>50 \%$ remuneration, which was significantly higher than the $29.2 \%$ of doctors under 35 years of age who desired $>50 \%$ remuneration $(p=0.03)$. In addition, a significantly larger proportion of young doctors (<35 years) (88.3\%) were willing to work during non-office hours, as compared to their older counterparts $(p<0.001)$. Furthermore, a significantly larger proportion of young doctors (95.0\%) were willing to enrol in HHPS, as compared to other age strata $(p=0.006)$.

\section{Appendix B: Unadjusted comparisons based on different age groups}

\begin{tabular}{|c|c|c|c|c|}
\hline VARIABLES & $<35$ YEARS & 35 TO 44 YEARS & $>44$ YEARS & P-VALUE \\
\hline $\begin{array}{l}\text { Number of patients seen by the doctor every day } \\
\text { in the hospital } \\
\quad<20 \\
20-30 \\
>30\end{array}$ & $\begin{array}{l}20.8 \\
29.2 \\
50.0\end{array}$ & $\begin{array}{l}27.0 \\
29.7 \\
43.3\end{array}$ & $\begin{array}{l}30.4 \\
30.4 \\
39.2\end{array}$ & $\begin{array}{l}0.51 \\
0.99 \\
0.55\end{array}$ \\
\hline Answering the follow-up queries by video chat or email & 82.5 & 89.2 & 87.0 & 0.58 \\
\hline $\begin{array}{l}\text { Answering the follow up queries through text message } \\
\text { or telephone call }\end{array}$ & 59.2 & 75.7 & 60.9 & 0.19 \\
\hline $\begin{array}{l}\text { Desire for an increase in remuneration: } \\
\text { No increase in remuneration } \\
\text { By } 20 \% \\
\text { By } 40 \% \\
\text { By }>\text { than } 50 \%\end{array}$ & $\begin{array}{c}3.3 \\
32.5 \\
35.0 \\
29.2\end{array}$ & $\begin{array}{c}2.7 \\
13.5 \\
32.4 \\
51.4\end{array}$ & $\begin{array}{l}13.0 \\
26.1 \\
17.4 \\
43.5\end{array}$ & $\begin{array}{c}0.006 \\
0.08 \\
0.25 \\
0.03\end{array}$ \\
\hline The system lends into a trial by doctors before adoption & 90.8 & 83.8 & 91.3 & 0.45 \\
\hline $\begin{array}{l}\text { The system is compatible with the needs of patients in the } \\
\text { community }\end{array}$ & 96.7 & 91.9 & 95.7 & 0.47 \\
\hline $\begin{array}{l}\text { The system is integrated with local healthcare system } \\
\text { in hospital }\end{array}$ & 94.2 & 91.9 & 95.7 & 0.82 \\
\hline $\begin{array}{l}\text { The system is accessible remotely on handheld devices } \\
\text { to review patient history at patient's home }\end{array}$ & 89.2 & 89.2 & 91.3 & 0.95 \\
\hline Patients being charged extra for homecare services & 80.0 & 78.4 & 87.0 & 0.69 \\
\hline Willingness to work during non-office hours & 88.3 & 56.8 & 65.2 & $<0.001$ \\
\hline Surgical specialties & 15.0 & 21.6 & 30.4 & 0.18 \\
\hline Answer the follow-up queries through a hospital visit & 90.8 & 78.4 & 91.3 & 0.11 \\
\hline EMR aids the adoption of HHPS & 85.0 & 91.9 & 82.6 & 0.49 \\
\hline EMR simplifies overall workflow & 97.5 & 97.39 & 5.7 & 0.89 \\
\hline I currently work in a system that has EMR & 54.2 & 75.7 & 95.7 & $<0.001$ \\
\hline Willingness to enrol into HHPS & 95.0 & 78.4 & 82.6 & 0.006 \\
\hline
\end{tabular}


Appendix $C$ demonstrates the unadjusted comparisons stratified based on gender. A significantly higher percentage of male doctors (67.2\%) were interested in answering the follow-up queries through text message or telephone call $(p=0.03)$, as compared to their female counterparts. Furthermore, a higher percentage of both male (92.0\%) and female (81.4\%) doctors considered that the system lending itself to a trial before adoption as an important factor for HHPS adoption ( $p=0.049)$. In addition, a significant large proportion of male doctors (69.3\%) were currently working with a system that has EMR compared to their female counterparts $(46.5 \%)(p<0.01)$.

\section{Appendice C: Unadjusted comparisons based on gender}

\begin{tabular}{|c|c|c|c|}
\hline VARIABLES & MALE & FEMALE & P-VALUE \\
\hline \multicolumn{4}{|l|}{ Number of patients seen by the doctor everyday in the hospital } \\
\hline$<20$ & 24.8 & 18.6 & 0.40 \\
\hline $20-30$ & 30.7 & 25.6 & 0.52 \\
\hline$>30$ & 36.5 & 55.8 & 0.20 \\
\hline Answering the follow-up queries by video chat or email & 83.9 & 86.1 & 0.74 \\
\hline Answering the follow up queries through text message or telephone call & 67.2 & 48.8 & 0.03 \\
\hline \multicolumn{4}{|l|}{ Desire for an increase in remuneration: } \\
\hline No increase in remuneration & 4.4 & 4.7 & 0.68 \\
\hline By $20 \%$ & 30.7 & 18.6 & 0.12 \\
\hline By $40 \%$ & 28.5 & 44.2 & 0.05 \\
\hline By $>$ than $50 \%$ & 36.5 & 32.6 & 0.64 \\
\hline The system lends into a trial by doctors before adoption & 92.0 & 81.4 & 0.049 \\
\hline The system is compatible with the needs of patients in the community & 96.4 & 93.0 & 0.36 \\
\hline The system is integrated with local healthcare system in hospital & 94.9 & 90.7 & 0.32 \\
\hline $\begin{array}{l}\text { The system is accessible remotely on handheld devices to review patient } \\
\text { history at patient's home }\end{array}$ & 89.1 & 90.7 & 0.76 \\
\hline Patients being charged extra for homecare services & 81.0 & 79.1 & 0.78 \\
\hline Willingness to work in non-office hours & 81.0 & 72.1 & 0.21 \\
\hline Surgical specialties & 21.2 & 9.3 & 0.08 \\
\hline Answer the follow-up queries through a hospital visit & 87.6 & 90.7 & 0.58 \\
\hline EMR aids the adoption of HHPS & 87.6 & 81.4 & 0.31 \\
\hline EMR simplifies overall workflow & 96.4 & 100.0 & 0.20 \\
\hline I currently work in a system that has EMR & 69.3 & 46.5 & $<0.01$ \\
\hline Willingness to enrol into a HHPS & 90.5 & 88.4 & 0.68 \\
\hline
\end{tabular}




\subsection{Multivariable analysis}

Appendix $\mathrm{D}$ demonstrates the results from the multivariable logistic regression analysis of the various outcome variables with the chosen independent variables as shown in Table 1. The need for an increase in remuneration by 40\% [OR: 140.2 (95\% Cl): 1.6 to 12595.0 ] and greater than 50\% [OR: 101.7 (95\% Cl): 2.3 to 4556.4 ] for service provision through HHPS, HHPS being integrated with the local healthcare system in the hospital [OR: $33.7(95 \% \mathrm{Cl}): 1.4$ to 835.3 ], and answering simple patient follow-up queries through video chat or email [OR: $9.6(95 \% \mathrm{Cl}): 1.0$ to 90.6$]$ were positively associated with the willingness of doctors to enrol in HHPS.
The need for an increase in remuneration by $20 \%$ [OR: 46.7 (95\% Cl): 2.9 to 765.4 ], 40\% [OR: 101.7 (95\% Cl): 5.4 to 1930.9 ], and greater than 50\% [OR: $10.4(95 \% \mathrm{Cl}): 0.8$ to 140.0] and interest in service provision through HHPS [OR: 9.8 (95\% Cl): 2.0 to 47.1 ] had a positive association with willingness to work during non-office hours. Factors such as willingness of doctors to work during non-office hours [OR: 340.2 (95\% Cl): 1.7 to 67721.0 ] and patients being charged extra for availing services through HHPS [OR: $25.2(95 \% \mathrm{Cl}): 1.3$ to 499.2] were found to be positively associated with a desire for increased remuneration among doctors in India.

Appendix D: Logistic regression over different outcome variables, * indicates statistical significance with $p<0.05, * *$ indicates tending to statistical significance with $0.1<\mathrm{p}<0.05$

\begin{tabular}{|c|c|c|c|}
\hline INDEPENDENT VARIABLES & ODDS RATIO & $\begin{array}{l}\text { [95\%CONF. } \\
\text { INTERVAL] }\end{array}$ & P-VALUE \\
\hline $\begin{array}{l}\text { Outcome variable: Willingness to work in non- office hours } \\
\text { Number of patients I see every day: } \\
<20 \\
20-30 \\
>30\end{array}$ & $\begin{array}{l}0.2 \\
0.3\end{array}$ & $\begin{array}{l}\text { Reference } \\
0-1.0 \\
0-1.5\end{array}$ & $\begin{array}{c}0.05^{* *} \\
0.13\end{array}$ \\
\hline $\begin{array}{l}\text { Desire for an increase in remuneration: } \\
\text { No increase } \\
\text { By } 20 \% \\
\text { By } 40 \% \\
\text { By > than } 50 \% \\
\text { Interest in service provisioning by HHPS }\end{array}$ & $\begin{array}{c}46.7 \\
101.7 \\
10.4 \\
9.8\end{array}$ & $\begin{array}{c}\text { Reference } \\
2.9-765.4 \\
5.4-1930.9 \\
0.8-140.0 \\
2.0-47.1\end{array}$ & $\begin{array}{l}<0.01^{*} \\
<0.01^{*} \\
0.08^{* *} \\
<0.01^{*}\end{array}$ \\
\hline $\begin{array}{l}\text { Age: } \\
\qquad 35 \\
\quad 35-44 \\
>44\end{array}$ & $\begin{array}{l}0.1 \\
0.2\end{array}$ & $\begin{array}{l}\text { Reference } \\
0-0.3 \\
0.1-1.1\end{array}$ & $\begin{array}{c}<0.001^{*} \\
0.07^{* *}\end{array}$ \\
\hline Male & 3.9 & $1.1-14.8$ & $0.04^{*}$ \\
\hline $\begin{array}{l}\text { Outcome variable: Desire for an increase in remuneration } \\
\text { Patients being charged extra for HHPS } \\
\text { Willingness to work in non-office hours }\end{array}$ & $\begin{array}{c}25.2 \\
340.2\end{array}$ & $\begin{array}{c}1.3-499.2 \\
1.7-67721.0\end{array}$ & $\begin{array}{l}0.03^{*} \\
0.03^{*}\end{array}$ \\
\hline $\begin{array}{l}\text { Outcome variable: Willingness to enrol into HHPS } \\
\text { Number of patients I see every day: } \\
\quad<20 \\
20-30 \\
>30\end{array}$ & $\begin{array}{c}0 \\
0.1\end{array}$ & $\begin{array}{l}\text { Reference } \\
0-1.7 \\
0-4.4\end{array}$ & $\begin{array}{c}0.09^{* *} \\
0.22\end{array}$ \\
\hline Answering the follow-up queries by video chat or email & 9.6 & $1.0-90.6$ & $0.04^{*}$ \\
\hline $\begin{array}{l}\text { Desire for an increase in remuneration: } \\
\text { No increase } \\
\text { By } 20 \% \\
\text { By } 40 \% \\
\text { By }>\text { than } 50 \%\end{array}$ & $\begin{array}{c}23.4 \\
40.2 \\
101.7\end{array}$ & $\begin{array}{c}\text { Reference } \\
0.7-799.1 \\
1.6-12595.0 \\
2.3-4556.4\end{array}$ & $\begin{array}{l}0.08^{* *} \\
0.03^{*} \\
0.02^{*}\end{array}$ \\
\hline The system is integrated with local healthcare system in hospital & 33.7 & $1.4-835.3$ & $0.03^{*}$ \\
\hline Willingness to work in non-office hours & 42.5 & 3.3-539.1 & $<0.01^{*}$ \\
\hline
\end{tabular}




\section{Discussion}

The objective of the study was to assess the knowledge, attitudes and perceptions of doctors in India regarding HHPS service provision. To the best of our knowledge, this is the first study of its kind. We have three salient findings:

1. The willingness of doctors to enrol in a HHPS was associated with a desire for increased remuneration. In addition, there was a positive association between increased need for remuneration and willingness of doctors to work during non-office hours. The other factors associated with willingness of doctors to enrol were willingness to answer follow-up queries by video chat or email, the integration of their system with a local healthcare system, and the willingness to work during non-office hours.

2. There was a significant age-based and gender based differential for willingness to work during non-office hours as a part of HHPS. It was likely that doctors under 35 years of age were more willing to work during nonoffice hours than the other age groups. Similarly, male doctors were more likely to be willing to work during non-office hours as compared to females. This suggests that young male doctors would most likely be the targeted employees for such systems in India.

3. Although a large majority of doctors indicated that hospital visits were important to follow-up on simple patient queries, several doctors indicated that simple patient queries in their practices could often be addressed using non-personal interactions like video chat or email.

The usage of the EMR improves the data quality, presentation, availability, along with doctor productivity. It reduces incorrect medications administered to patients, data input errors and increases quality assurance. $[10,11,13,14]$ This may be an important factor when the physicians offer healthcare services from a distance through different means of communication such as emails, telephones, and text messages. The use of EMR also increases treatment quality by increased exchange and flow of information between monitoring and administrative functions, compliance with the regulations and the ability to integrate graphic data such as electrocardiograms, alarms and warning systems. $[10,11,13,14]$ This increases the ability of physicians to make right diagnoses for patients. EMR usage reduces the mortality rate of patients. [13] It also saves physician and personnel time, and reduces transcription costs. $[15,16]$ The use of EMRs may prove to be beneficial for the adoption of HHPS in India.
There is extremely limited access to medical care in India because the majority of people in India live below the poverty line. Moreover, India's healthcare industry lacks a medically insured population; and hence, there are high out of pocket expenditures. [26]

In addition, secondary/tertiary and outpatient care is also in need of improvement. Most of the time, patients are hesitant to approach primary care doctors and pursue specialist consultations instead. This increases the burden on the specialist doctors as they have less time to diagnose these patients.

The insurance payment structure is almost exclusively retroactive in India. [25] There is a need for a change in the payment structure so that the beneficiaries are covered for medical costs upfront, instead of them incurring all the expenditure and waiting for longer periods of time to get reimbursed. The state-sponsored or community health insurance plans provide coverage for inpatient primary care. [25] Outpatient coverage or payments for preventative primary care are virtually non-existent and there is a lack of universal healthcare coverage in India.

Many concierge physicians use telephone and email to communicate with their patients. [17] On the other hand, many doctors also avoid email and telephone consultations because the insurers do not reimburse them for phone or email consultations. [18] Some of the barriers to the implementation of Health Information Technology (HIT) systems in India include difficulty in understanding how the systems work and uncertain financial benefits in the face of high upfront costs. [6] The EMR and the Internet could improve doctor/patient communication and patient compliance. [19] The improvement in communication could potentially increase the overall benefits for both doctors and patients. Moreover, EMRs could also improve decisionmaking, thus increasing compliance for patients. HIT system design should take into account how clinicians work. [20] This may be important to increase the usage of systems by the clinicians and thus increase the overall advantage for patients. Moreover, software developers should also allow systems to be tailored to the special needs of patients and providers. [21] This would prove beneficial for both doctors and patients.

The major point of concern regarding concierge practice for a few physicians is that they may encounter peer disapproval. [22] Peers can have a positive or negative influence on providers willing to practise through a HHPS. Both physicians and patients could benefit when the system is adopted in 
areas where the likelihood its usage is higher. Concierge medicine is likely to be adopted in areas where older people live. [23] Moreover, the need for the system among patients is important, and it may also be important for the successful adoption of HHPS. It is very likely that patients who call their primary care physicians during evenings or weekends are unable to obtain care. [24] However, it is important for the physicians to be willing to provide services during the time when the patients require these services. Many of the chronic and preventive care issues can be handled by telephone calls or email encounters. [24]

Research on the perceptions of doctors regarding the development of HPPS is scant. Moreover, little research exists on the effectiveness of HHPS. The first factor is the willingness of doctors to enrol in HHPS, which also influences the functioning of HHPS and is based on the desire for an increased remuneration. The second important factor for the functioning of HHPS is the willingness of doctors to work during non-office hours. The third factor is the desire for an increased remuneration among doctors for providing healthcare services, which influences the functioning of doctors during non-office hours. The desire for an increase in remuneration among doctors is co-expressed with the thought that patients should be charged extra for these services. The perceptions of doctors regarding increased remuneration were also associated with them answering the follow-up queries through text message or telephone call.

There are several potential implications for implementing HHPS in a developing nation like India. First, HHPS will ensure round the clock availability of doctors for patients. This may reduce the number of deaths that may arise because of critical cases. Secondly, HHPS will reduce the burden on doctors due to hospital visits, as they will be able to answer simple patient queries through email or telephone calls. This will help patients to avoid hospital visits in case of minor issues. And, this will ensure that the patients in need of care are being diagnosed accurately. Thirdly, establishment of a HHPS might serve to establish 'gatekeeper' physicians for patients enrolled in the system. [2] A HHPS physician may examine a patient's medical condition and make referrals to specialists, when necessary. [2] This likely would avoid self-referrals (which is common in India), reduce burden on specialist offices and reduce healthcare costs substantially.

\section{Limitations}

This study is limited to the perceptions of doctors toward the provision of healthcare services at patients' homes. It also did not look at the challenges during and after the implementation of HHPS, which could be a topic of future research. The sample for the study was collected through convenience sampling, which is a major limitation of the study. Moreover, the impact of socioeconomic status of patients, which would largely govern the adoption of HHPS could not be studied at this time.

\section{Conclusions}

Our study has assessed the determinants and beliefs of doctors in India and would be instrumental in adopting HHPS on a large scale. The desire for extra remuneration is found to be the primary reason for the willingness of doctors to work during non-office hours and thus to enrol in HHPS. The HHPS can ensure round the clock availability of doctors for patients, which can reduce the number of deaths that may arise because of critical cases in countries like India. The HHPS physician can make referrals to specialists when necessary which would avoid self-referrals and reduce burden on specialist clinics.

\section{Competing interests}

The authors declare they have no competing interests.

\section{References}

1. Carnahan SJ. Law, Medicine, and Wealth: Does Concierge Medicine Promote Health Care Choice or is it a Barrier to Access? Stanford Law Pol Rev. 2006;17(1):121-164.

2. Agarwal N, Sebastian MP, Agarwal S. Assessing the adoption of a home health provisioning system in India: An analysis of patients. Health Policy Technol. 2006;5:74-83.

3. Braibish J. Physicians seek a more personalized approach in retainer-based practice. Mo Med. 2013;110(3):172-4.

4. Fields R. Retainer practices good for patients and physicians. Md Med. 2006;7(2):4.

5. Häyrinen K, Saranto K, Nykänen P. Definition, structure, content, use and impacts of electronic health records: a review of the research literature. Int J Med Inform. 2008;77(5):291-304.

6. Miller RH, Sim I. Physicians' use of electronic medical records: barriers and solutions. Health Aff. 2004; 23(2):116-126.

7. Oechsner R, Pfeffer M, Pfitzner L, Binder H, Müller E, Vonderstrass T. From overall equipment efficiency (OEE) to overall Fab effectiveness (OFE). Materials Science in Semiconductor Processing. 2002; 5(4):333-339.

8. Edwards M, Moczygemba J. Reducing medical errors through better documentation. Health Care Manag. 2004;23(4):329-333.

9. Gavirneni S, Kulkarni V. Concierge medicine applying rational economics to health care queuing. Cornell Hospitality Quarterly. 2014;55(3):314-325.

10. Antoine W. Electronic miracle, Memorial Hermann put its patient files online and watch its revenue grow. Health Forum J. 2002; 45(4):34-35 
11. Asher JR. Time and money. A look at message automation via a computerized patient record. MGMA Connexion/Medical group Management Association. 2003;3(9):28-29.

12. Alexander GC, Kurlander J, Wynia MK. Physicians in retainer ('concierge') practice. A national survey of physician, patient, and practice characteristics. J Gen Inter Med. 2005;20(12):1079-83.

13. Hammond J, Johnson HM, Varas R, Ward CG. A qualitative comparison of paper flow sheets vs a computer-based clinical information system. Chest. 1991;99(1):155-157.

14. Pierpont GL, Thilgen D. Effect of computerized charting on nursing activity in intensive care. Critical Care Medicine 1995;23(6): 1067-1073.

15. Carpenter D. Three approaches to ROI. Hosp Health Netw. 2005; 79(5):9-12

16. O'Connor PJ, Crain AL, Rush WA, Sperl-Hillen JM, Gutenkauf JJ, Duncan JE. Impact of an electronic medical record on diabetes quality of care. Ann Fam Med. 2005;3(4):300-306.

17. Devon MH, Linda G, John CG. National Center for Policy Analysis Health Information Technology: Benefits and Problems (Policy Report No. 327). Dallas, TX. 2005.

18. Wiebe C. Doctors still slow to adopt email communication Medscape Money \& Medicine. 2001;2(2).

19. Kilo CM. Transforming care: medical practice design and information technology. Health Aff. 2005;24(5):1296-1301.

20. Kibbe DC, McLaughlin CP. The alternative route: hanging out the unmentionables for better decision making in health information technology. Health Aff. 2008;27(5):w396-w398.

21. Overhage JM. Health information exchange:'lex parsimoniae'. Health Aff. 2007;26(5): w595-w597.

22. Brennan T. 'Concierge' Practice and the Profession's Contract with Society. The Virtual Mentor: VM. 2003;5(11):170-177.

23. Bodenheimer T, Pham HH. Primary care: current problems and proposed solutions. Health Aff. 2010;29(5):799-805.

24. Casalino LP. Analysis and Commentary. A Martian's prescription for primary care: overhaul the physician's workday. Health Aff. 2010; 29(5):785-790.

25. Healthcare in India. Available from: http://assets.ce.columbia.edu/ pdf/actu/actuindia.pdf

26. World Health Organization: National Health Accounts in India. 2005. Available from: http://planningcommission.nic.in/reports/ genrep/health/National_Health_Account_04_05.pdf 